\title{
Optimization of TIG Process Parameter in Improving Mechanical Properties of S304 Stainless Steel Using a Grey Based Taguchi Method
}

\author{
Naveen Pandey ${ }^{1}$, Dinesh Dubey ${ }^{2}$ \\ ${ }^{1}$ Department of Mechanical Engineering, M.Tech Research Scholar RSR Rungta College of Engineering and Technology, \\ Chhattisgarh, India \\ ${ }^{2}$ Department of Mechanical Engineering, HOD, RSR Rungta College of Engineering and Technology, Chhattisgarh, India
}

\begin{abstract}
Article Info

Volume 8, Issue 5

Page Number : 01-06

Publication Issue :

September-October-2021

Article History

Accepted : 03 Sep 2021

Published: 13 Sep 2021

Tungsten inert gas welding is popular known welding technique for ferrous \& nonferrous. Stainless steel grade 3HQ (S30430) is a specialized wire grade with very wide usage for manufacturer of stainless steel fastener. It has now totally replaced Grade 384 and 305 for heading application. The stable austenitic structure makes 302HQ nonmagnetic, even after substantial cold work, and also results in excellent toughness, even down to cryogenic temperatures. This paper attempts in optimizing the Tungsten Inert Gas (TIG) welding process parameter. The effect of various parameters and their influence is important to determine the strength of welded joint. To obtain a good quality weld, it is therefore, essential to control the input welding parameters. Therefore appropriate selection of input welding parameter is necessary in order to obtain a good quality weld and subsequently increase the productivity of manufacturing industry. This paper present multi objective optimization using grey relation analysis (GRA) for S30430 with TIG process to determine the suitable selection of parameters Experiment were conducted according to Taguchi's design of experiments (DOE) with orthogonal array L9 is used, mathematical model was developed using parameters such as speed ( $\mathrm{mm} / \mathrm{min})$, current (Amp), voltage $(\mathrm{V})$, depth of penetration $(\mathrm{mm})$. After conducting experiment and collecting data, signal to noise ratio were determined by using Minitab18 and it is used to obtain optimum level for every input parameter.

Keywords - TIG welding, Grey relation analysis (GRA), Taguchi methodology, Signal to Noise ratio, Minitab18.
\end{abstract}

\section{INTRODUCTION}

In today's scenario welding of thin sheets is being the challenging task in the field of Engineering.
The major reason behind this is perfection, which is being the nominal factor considered during the joining process of sheets because, in such joining of plate, two pass and three pass welding cannot 
be carried out in thin sheets below $4 \mathrm{~mm}$, as under welding results in predominant reduction in strength and over weld results in formation of hole. Hence optimization ofTweld parameter plays a predominant role in joining ofTthin sheets. This research is to make the thin sheet welding easy and compatible by optimizing the process parameters. Welding is great significant operation in any manufacturing industry [1]. It is absolutely necessary to optimize different welding process parameter, so that industry achieve reliable, productive and good quality product. Nowdays global manufacturing industries are more focused toward $\mathrm{R} \& \mathrm{D}$. To investigate welding process parameter such as current, voltage, inert gas, pulsed on/off time etc. TIG welding process is commonly used operation for joining of two materials with the application of heat. TIG is also known as Gas Tungsten Arc Welding (GTAW). Arc is maintained between non- consumable electrode and work piece in a protective inert gas atmosphere [2]. The various studies are done to investigate the influence of welding process parameter on tensile strength [3].

\section{Taguchi Design of Experiment}

Taguchi DOE is a popular statistical technique that provides a proper and efficient methodology for process optimization. Taguchi method allows us improve the consistency of production. Taguchi design recognizes that not all factors that cause variability can be controlled. These uncontrollable factors are called noise factor. Taguchi design tries to identify controllable factor that minimize the effect of noise factor. During experimentation, you manipulate control factor to evaluate variability that occurs and then determine optimal control factor setting, that minimize the process variability.
Process designed with this goal produce more consistent output and performance regardless of the environment in which it is used [4]. It is world widely used for product design and process optimization [5-10]. As a result, time as well as cost is reduced considerably.

Taguchi DOE methodology uses orthogonal array that gives different combinations of parameters and their levels for each experiment. According to this methodology, every parameter is studied with minimal number of necessary experiments only [11].

\section{Layout of Experiment}

In order to perform experiment for data collection following sequence is followed.

- Selecting the base and filler material.

- Selecting pulsed TIG welding process parameters.

- Finding the upper and lower limits of the identified process parameters.

- Select the appropriate orthogonal array.

- Conduction of the experiments as per the selected orthogonal array.

- Find the optimum condition.

3.1 Selecting base material and there mechanical properties.

S30430 stainless steel sheets of dimension $100 \times 150$ $\times 3 \mathrm{~mm}$ are welded autogenously with butt joint without edge preparation [12]. The chemical composition of S30430 stainless steel sheet is given in Table1 
Table 1: Chemical Composition of base material (wt \%)

\begin{tabular}{cccccccc}
\hline US DESIGNATION & $\% \mathrm{Cr}$ & $\% \mathrm{Ni}$ & $\% \mathrm{C}$ & $\% \mathrm{Mn}$ & $\% \mathrm{Si}$ & $\% \mathrm{P}$ & $\% \mathrm{~S}$ \\
\hline $\mathrm{S} 30430$ & 18 & 8 & 0.03 & 2 & 0.75 & 0.045 & 0.03 \\
\hline
\end{tabular}

Table 2: Mechanical Properties of $\mathrm{S} 30430$

\begin{tabular}{ccccc}
\hline Tensile strength & Yield Strength & Hardness & Melting Point & Density \\
\hline 564 MPA & 241 MPA & B80 HBN & $1400-1450^{\circ} \mathrm{C}$ & $8 \mathrm{~g} / \mathrm{cm}^{3}$ \\
\hline
\end{tabular}

3.2 Identify the pulsed welding process parameter.

From the literature survey [13-14] and previous work done the most important process parameters which are having greater influence on the weld bead geometry. They are welding speed, welding current, welding voltage and gas flow rate.

3.3 Level of working range

Numbers of experiment has been conducted by varying one of the process parameters and keeping the others constant [13-14]. The working range of the process parameters are shown in Tables 3.

Table 3: Process parameters working range at standoff distance $2 \mathrm{~mm}$.

\begin{tabular}{lcccc}
\hline Factor/Process & Cod & Level & Level & Level \\
Parameter & $\mathrm{e}$ & 1 & 2 & 3 \\
\hline Welding current & $\mathrm{A}$ & 140 & 150 & 160 \\
(Amp) & & & & \\
Welding voltage (V) & $\mathrm{B}$ & 24 & 25 & 26 \\
Welding speed & $\mathrm{C}$ & 165 & 179 & 193 \\
$(\mathrm{~mm} / \mathrm{min})$ & & & & \\
\hline
\end{tabular}

\subsection{Orthogonal array is selected}

Process parameters selected for this experiment is three, and the level of each parameter is three. Taguchi orthogonal design of experiment uses a special set of predefined arrays called orthogonal arrays (OAs) to design the plan of experiment [15]. These standard arrays provide the way to full information of all three factors that affects the process performance. For the present experimental work, three factors with their three levels are usedfor which the corresponding orthogonal array is L9 as shown in below table.

Table 4: Orthogonal Array L9 (Minitab18)

\begin{tabular}{cccc}
\hline Experiment No. & & Process Parameter & \\
& A & B & C \\
\hline 1 & 1 & 1 & 2 \\
2 & 1 & 3 & 3 \\
3 & 1 & 1 & 3 \\
4 & 2 & 2 & 1 \\
5 & 2 & 3 & 3 \\
6 & 2 & 1 & 1 \\
7 & 3 & 2 & 2 \\
9 & 3 & 3 & \\
\hline
\end{tabular}




\subsection{Conduction of experiments}

By putting the values of three levels of three parameters in L9 Orthogonal array, the nine set of experiments with different values of parameters and results are obtained as fallows. The $\mathrm{S} / \mathrm{N}$ ratio help in measuring the sensitivity of quality characteristic to external noise factor which is not under control. Taguchi techniques are experimental design optimization techniques which use standard Orthogonal Arrays (OA) for forming a matrix of experiments. Using an OA to design the experiment helps the researcher to understand the influence of different controllable factors on the quality characteristics and the variations in a fast and economic way. The highest $\mathrm{S} / \mathrm{N}$ ratio indicates more impact of the process parameter on the performance characteristics. On the basis of characteristic three $\mathrm{S} / \mathrm{N}$ ratios are available namely lower the better, higher the better and nominal the better. In this paper higher the better is used for maximizing depth of penetration [16].

$$
S / N \text { Ratio }=-10 \log 1 / n\left[\sum_{i=0} 1 / y \mathrm{R}_{i}\right]
$$

Signal-to Noise ratio (S/N ratio) was first introduced by Sir Michael A Choma. The purpose of the Signal-toNoise ratio ( $\mathrm{S} / \mathrm{N}$ ratio) is to find which design parameters significantly affect the quality characteristic. In the Taguchi Method the term Signal represents the desirable value (mean) for the output characteristic and the term Noise represents the undesirable value (standard deviation) for the output characteristic. The $\mathrm{S} / \mathrm{N}$ ratio is defined as $n=10 \log$ (M.S.D.) Where, M.S.D is the mean square deviation for the output characteristic. To obtain optimal welding performance, higher the better quality characteristic can be taken and $\mathrm{S} / \mathrm{N}$ ratio is calculated foreach experiment.

Where $\mathrm{n}$ is the repetition of output response in the same trial and is the response.

Table 5: Experimental Results

\begin{tabular}{cccccc} 
Experimental No. & A & B & C & Penetration & S/N Ratio \\
\hline 1 & 140 & 24 & 165 & 5.4 & 14.6479 \\
2 & 140 & 25 & 179 & 5.2 & 14.3201 \\
3 & 140 & 26 & 193 & 5.0 & 13.9794 \\
4 & 150 & 24 & 179 & 5.3 & 14.4855 \\
5 & 150 & 25 & 193 & 5.1 & 14.1514 \\
6 & 150 & 26 & 165 & 5.4 & 14.6479 \\
7 & 160 & 24 & 193 & 5.3 & 14.4855 \\
8 & 160 & 25 & 165 & 6.9 & 16.7770 \\
9 & 160 & 26 & 179 & 6.4 & 16.1236 \\
\hline
\end{tabular}

Table 6: Response Table for Signal to Noise Ratios (Larger is better)

\begin{tabular}{rccc}
\hline Level & $\begin{array}{c}\text { Welding current } \\
(\mathrm{amp})\end{array}$ & $\begin{array}{c}\text { Welding voltage } \\
(\mathrm{v})\end{array}$ & $\begin{array}{c}\text { Welding speed } \\
(\mathrm{mm} / \mathrm{min})\end{array}$ \\
\hline 1 & 14.32 & 14.54 & 15.36 \\
2 & 14.43 & 15.08 & 14.98 \\
3 & 15.80 & 14.92 & 14.21 \\
\hline Delta & 1.48 & 0.54 & 1.15 \\
\hline Rank & 1 & 3 & 2 \\
\hline
\end{tabular}


Table 7: Response Table for Mean

\begin{tabular}{rccc}
\hline Level & $\begin{array}{c}\text { Welding current } \\
(\mathrm{amp})\end{array}$ & $\begin{array}{c}\text { Welding voltage } \\
(\mathrm{v})\end{array}$ & $\begin{array}{c}\text { Welding speed } \\
(\mathrm{mm} / \mathrm{min})\end{array}$ \\
\hline 1 & 5.2 & 5.333 & 5.9 \\
2 & 5.267 & 5.733 & 5.633 \\
3 & 6.2 & 5.600 & 5.133 \\
\hline Delta & 1.0 & 0.400 & 0.767 \\
\hline Rank & 1 & 3 & 2 \\
\hline
\end{tabular}

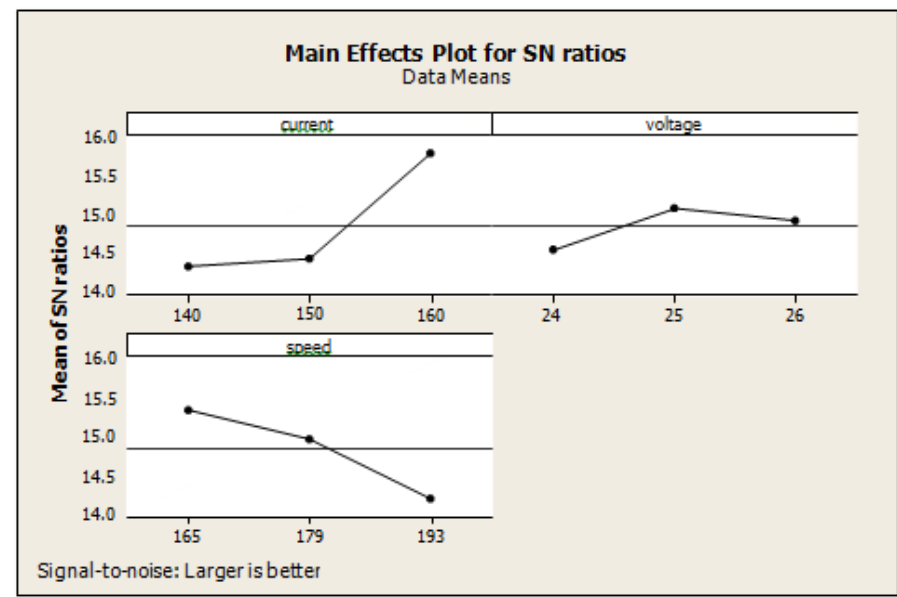

Fig 1 : Main Effect plot for S/N Ratio

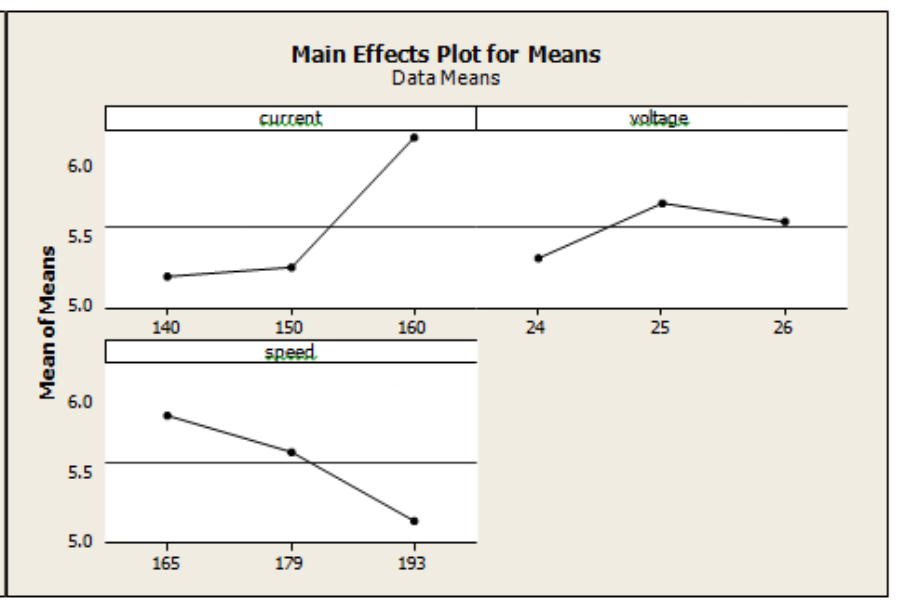

Fig 2 : Main Effect plot for Mean

\section{ANOVA Approach}

Analysis of variance (ANOVA) is a method for testing the hypothesis that there is no difference between two or more population means. ANOVA is a hypothesis testing technique used to test the equality of two or more population (or treatment) means by examining the variances of samples that are taken.

Table 8 : Analysis of Variance for SNRA1, using Adjusted SS for Tests

\begin{tabular}{llllllcc}
\hline Source & DF & Seq SS & Adjss & AdjMS & F & P & $\begin{array}{c}\% \\
\text { contribution }\end{array}$ \\
\hline Current & 2 & 4.0708 & 4.0708 & 2.0354 & 6.71 & 0.130 & 56.46 \\
Voltage & 2 & 0.4649 & 0.4649 & 0.2325 & 0.77 & 0.566 & 6.45 \\
Speed & 2 & 2.0671 & 2.0671 & 1.0335 & 3.41 & 3.41 & 28.67 \\
Error & 2 & 0.6066 & 0.6066 & 0.3033 & & & \\
\hline Total & 8 & 7.2094 & & & & & \\
\hline
\end{tabular}




\section{Integration of Taguchi method Grey Relation Analysis}

In the grey relation analysis experimental results were first normalized and then grey relation coefficient was calculated from normalized experimental data to express the relationship between desired and actual experimental data. Then the grey relation grade was computed by averaging the grey relation coefficient corresponding to each process response [17].
In Grey Relation Analysis when the range of the sequence is large or the standard value is enormous, the function of the factor is neglected [18]. However, if the factor goal and direction are different, grey relation might produce incorrect results. There preprocess of the data which are related to a group of sequence which is called grey relational generation. Experimental results are normalized in the range between zero to one. The normalization is done three different ways.

\subsection{Grey relation generation(GRA)}

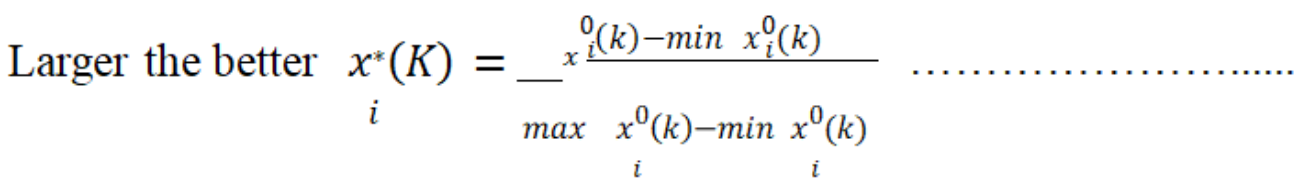

$$
\begin{aligned}
& \begin{aligned}
\text { Smaller the better } x^{*}(K)= & { }_{-} \max \frac{x^{0}(k)-}{x_{i}^{0}(k)} \\
& \max x^{0}(k)-\min x^{0}(k) \\
i & i_{i}
\end{aligned}
\end{aligned}
$$

Where $x^{*}(K)=$ value after data preprocessing, $\max x^{0}(k) \& \min x^{0}(k)$ are max. \& min value of $x^{0}(k)$

$$
i \quad i \quad i \quad i
$$

$\operatorname{SNRA} x^{0}(k)=14.6479, \max x^{0}(k)=16.7770, \min x^{0}(k)=13.9794, i=1,2,3 \ldots \ldots . \mathrm{m}$

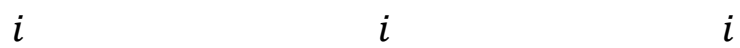

$k=1,2,3 \ldots \ldots \ldots \ldots \ldots . . . n, m=$ no. experimental data

Table 9 : Normalization of experimental data

\begin{tabular}{cc}
\hline Sample No. & Penetration $(\mathrm{mm})$ \\
\hline Reference Sequence & 1 \\
1 & 0.2389 \\
2 & 0.12178 \\
3 & 0 \\
4 & 0.1809 \\
5 & 0.06148 \\
6 & 0.6685 \\
7 & 0.06848 \\
8 & 1 \\
9 & 0.7664
\end{tabular}

\subsection{Grey Relation coefficient}

After pre-processing, a grey relation coefficient can be calculated with the preprocessed sequence. It expresses the relationship between ideal and actual normalized experimental results. Grey relation coefficient can be expressed as

$$
\xi(k) i=\frac{\Delta \min +\xi \Delta \max }{\Delta(k)+\xi \Delta \max }
$$


Taking $\xi=0.5, \Delta \max =1, \Delta \min =0, \Delta 1=1-0.23891=0.76109$

Table 10: Grey Relation coefficient of each performance characteristic

\begin{tabular}{cccc}
\hline $\begin{array}{c}\text { Sample } \\
\text { No. }\end{array}$ & $\begin{array}{l}\text { Grey Relation } \\
\text { Coefficient }\end{array}$ & $\begin{array}{l}\text { Grey Relation } \\
\text { Grade }\end{array}$ & $\begin{array}{c}\text { Ran } \\
\mathrm{k}\end{array}$ \\
\hline 1 & 0.3964 & 0.3964 & 4 \\
2 & 0.362786 & 0.362786 & 6 \\
3 & 0.3333 & 0.3333 & 9 \\
4 & 0.3790 & 0.3790 & 5 \\
5 & 0.34757 & 0.34757 & 8 \\
6 & 0.601322 & 0.601322 & 3 \\
7 & 0.349279 & 0.349279 & 7 \\
8 & 1 & 1 & 1 \\
9 & 0.68157 & 0.68157 & 2 \\
\hline
\end{tabular}

Table 11: Analysis of Variance for Grey Relation Grade

\begin{tabular}{cccccccc}
\hline Source & DF & Seq SS & Adjss & AdjMS & F & P & $\begin{array}{c}\% \\
\text { contributi } \\
\text { on }\end{array}$ \\
\hline Current & 2 & 0.15890 & 0.158 & 0.07945 & 5.6 & 0.15 & 38.670 \\
& & & 90 & & 3 & 1 & \\
Voltage & 2 & 0.06594 & 0.065 & 0.03297 & 2.3 & 0.30 & 16.04 \\
& & & 94 & & 4 & 0 & \\
Speed & 2 & 0.15786 & 0.157 & 0.07893 & 5.5 & 0.15 & 38.417 \\
& & & 86 & & 9 & 2 & \\
Error & 2 & 0.02822 & 0.028 & 0.01411 & & & \\
& & & 22 & & & & \\
\hline Total & 8 & 0.41091 & & & & &
\end{tabular}

\section{RESULTS AND DISCUSSION}

In this research article, L9 orthogonal array is used to investigate the influence of welding process parameter, welding current found to be the most crucial factor that effect the process characteristic. By using statistical technique ANOVA, that will assesses the contribution of each parameter. The statistical software Minitab 13 is used to investigate the significance contribution of each parameter. It has been found that experiment no. 8 has the optimum parameter setting for better control of the process characteristics. By using Grey Relation Analysis integrated with Taguchi Method, higher Grey Relation Grade (GRG) will have better multiple responses; Rank 1 is given to higher GRG. Comparing the results obtained from both the method i.e taguchi \& GRA is has been found that welding current is most crucial parameter which affects the performance characteristics followed by welding speed and welding voltage. In Taguchi experiments, we always want to maximize the $\mathrm{S} / \mathrm{N}$ ratios and the 
means were maximized when the Current was 160Amp, voltage 25 Volt and welding speed was 165 $\mathrm{mm} / \mathrm{min}$ based on these results, we should set the factor at the calculated value.

Table 12 : Response Table for levels

\begin{tabular}{lll}
\hline Welding Current & Level 1 & $160 \mathrm{Amp}$ \\
Welding Voltage & Level 3 & $25 \mathrm{Volt}$ \\
Welding speed & Level 2 & $165 \mathrm{~mm} / \mathrm{min}$
\end{tabular}

So, on the basis of these results we can say that Tensile Strength of stainless steel will be higher when we will use Current at 160A, 25 Voltage and Welding speed $165 \mathrm{~mm} / \mathrm{min}$. So these are optimum welding parameters on which we can attain the higher tensile strength of Stainless Steel S30430 welds.

\section{Future Scope}

Different techniques are used for investigation of processes and process parameter. The most common techniques is trial and error method based experiment, it is time consuming and uneconomical. The results obtained is verified by various other optimization techniques is used to get optimum results i.e Genetic Algorithm (GAs), fuzzy logic, Artificial Neural Network (ANN), Finite Element Method (FEM).

\section{Acknowledgement}

I would gratefully acknowledge to, Dr.S.Alam, Integral University, Lucknow, Uttar Pradesh, India, for providing research facility \& guidance, I also thankful to Dr. Ishtiyaq Ahmad, NIT-Raipur, Chhattisgarh, India, for their consistent help in writing this research paper.

\section{REFERENCES}

[1]. Dinesh Kumar R, Elangovan S, Siva Shanmugam N, June, 2014 "Parametric optimization of Pulsed TIG Welding Process in Butt Joining of 304L Austenitic Stainless Steel Sheet" IJRET: International Journal of Research in Engineering and Technology, eISSN: 23191163, pISSN: 2321-7308

[2]. S Elangovan, $\mathrm{S}$ Venkateshwaran and $\mathrm{K}$ Prakasan, 2012 'International Journal of Advanced Engineering Research and Studies. Vol. I/ Issue III/April-June, E-ISSN2249-8974.

[3]. Sanap Deepali, Prof. Galhe D.S, Prof. Burkul R.M, May, 2015 “A Review Paper on Effect of welding speed and groove angle on strength of butt joint using TIG welding” International Journal Of Engineering Science \& Research Technology ISSN:22779655

[4]. Zulquernain Mallick 'Optimization of operating parameters for a back-pack type grass trimmer' 2007, Elsevier

[5]. Wang W.H, and Tarng Y.S, 1998, "Design Optimization of cutting parameters for turning operations based on the Taguchi method". Journal of Materials Processing Technology, 84, pp. 122-129.

[6]. Syrcos G.P, 2003, "Die casting process Optimization using Taguchi methods". Journal of Materials Processing Technology, 135, pp. 68-74.

[7]. Ghani, J.A, Choudhury I.A, and Hassan, H.H, 2004, "Application of Taguchi method in the Optimization of end milling parameters". Journal of Materials Processing Technology, 145, pp. 84-92.

[8]. George, P.M, PillaiN, and Shah, N, 2004, "Optimization of shot peening parameters using Taguchi technique". Journal of Materials Processing Technology, 153, pp. 925-930.

[9]. Yang H.J, Hwang P.J, and Lee S.H, 2002, “A study on shrinkage compensation of the SLS process by using the Taguchi method". International Journal of Machine Tools and Manufacture, 42, pp. 1203-1212. 
[10]. Lee B.H, Abdullah J, and Khan Z.A, 2004, "Optimization of rapid prototyping parameters for production of flexible ABS object". Journal of Materials Processing Technology, Accepted (In Press).

[11]. Phadke M.S, 1989, "Quality Engineering Using Robust Design”. Prentice Hall International Inc., New York.

[12]. P.K. Giridharan, N.Murugan 2009 'Optimization of pulsed GTA welding process parameters for the welding of AISI 304L stainless steel sheets'The International Journal of Advanced Manufacturing TechnologyJanuary 2009, Volume 40, Issue 56, pp 478-489

[13]. Sunadaresan S, Janaki Ram G.D, "Use of magnetic arc oscillation for grain refinement of gas tungsten arc welds in titanium alloys". SciTechnol Weld Joining 1999;4 (3):151-60.

[14]. Kumar A, Sundarrajan S. "Selection of welding process parameters for the optimum but joint strength of an aluminum alloy". Mater Manuf Process 2006;21(8):789-93.

[15]. Amitava Mitra, 2012 'Experimental Design and the Taguchi Method' Fundamentals of Quality Control and Improvement: Solutions Manual to Accompany, Third Edition. Print ISBN: 9780470256978 Online ISBN: 9780470409831

[16]. Tarng YS, Juang SC, Chang CH (2002) The use of grey-based Taguchi methods to determine submerged arc welding process parameters in hardfacing. J Mater Process Technol 128:1-6

[17]. HosseinHasani, SomayehAkhavanTabatabaei, GhafourAmiri "Grey Relational Analysis to Determine the Optimum Process Parameters for Open-End Spinning Yarns" Journal of Engineered Fibers and Fabrics Volume 7, Issue $2-2012$

[18]. Ching-kaochang and H.S.Lu, 2006 'Design optimization of cutting parameters for side milling operations with multiple performance characteristics' The International Journal of
Advanced Manufacturing Technology February 2007, Volume 32, Issue 1-2, pp 18-26

\section{Cite this article as :}

Naveen Pandey, Dinesh Dubey, "Optimization of TIG Process Parameter in Improving Mechanical Properties of S304 Stainless Steel Using a Grey Based Taguchi Method", International Journal of Scientific Research in Science, Engineering and Technology (IJSRSET), Online ISSN : 2394-4099, Print ISSN : 2395-1990, Volume 8 Issue 5, pp. 77-85, SeptemberOctober 2021. Available at doi : https://doi.org/10.32628/IJSRSET218470 Journal URL : https://ijsrset.com/IJSRSET218470 